\title{
Dexamethasone Suppresses Expression of Nuclear Factor-kappaB in the Cells of Tracheobronchial Lavage Fluid in Premature Neonates with Respiratory Distress
}

\author{
ZUBAIR H. AGHAI, SANJAY KUMAR, SABEENA FARHATH, MARY ANN KUMAR, JUDY SASLOW, TAREK NAKHLA, \\ RIVA EYDELMAN, LOUISE STRANDE, GARY STAHL, CHARLES HEWITT, MIRJANA NESIN, AND IRFAN RAHMAN
}

Department of Pediatrics [Z.H.A., S.K., S.F., M.A.K., J.S., T.N., R.E., L.S., G.S., C.H.], Cooper University Hospital-Robert Wood Johnson Medical School, Camden, NJ 08103; Department of Pediatrics [M.N.], Boston University School of Medicine, Boston, MA 02118; Department of Environmental Medicine [I.R.], Lung Biology and Disease Program, University of Rochester Medical Center, Rochester, NY 14642

\begin{abstract}
Nuclear Factor-kappaB $(\mathrm{NF}-\kappa \mathrm{B})$ plays a central role in regulating the key mediators of inflammation involved in acute lung injury. The anti-inflammatory effect of steroids by suppressing pro-inflammatory cytokines may be mediated by inhibition of transcription factor NF- $\kappa \mathrm{B}$. The objective of this study was to determine the effect of glucocorticoid therapy on the expression of NF- $\kappa \mathrm{B}$ in the cells of tracheobronchial lavage fluid (TBLF) in premature neonates with respiratory distress. Nineteen premature neonates requiring mechanical ventilation and receiving glucocorticoids were enrolled. Their gestational age (mean $\pm \mathrm{SD}$ ) was $25.0 \pm 1.2 \mathrm{wk}$, birth weight $714 \pm 105 \mathrm{~g}$ and age of starting dexamethasone was $33 \pm 15 \mathrm{~d}$. Tracheobronchial lavage fluid was collected before and $48-72 \mathrm{~h}$ after starting dexamethasone. NF- $\kappa \mathrm{B}$ expression was measured by immunocytochemistry using mouse MAb against the p65 subunit of $\mathrm{NF}-\kappa \mathrm{B}$ on cytospin slides. The percent of cells stained and the intensity staining index were significantly higher before starting dexamethasone compared with after steroid therapy. Localization of $\mathrm{NF}-\kappa \mathrm{B}$ was significantly decreased in the cytoplasm and nuclei of mononuclear cells after initiation of dexamethasone therapy. The concentration of IL-8 was also significantly lower after starting dexamethasone. In conclusion, dexamethasone suppressed the expression of NF- $\kappa \mathrm{B}$ in the cytoplasm and nuclei of mononuclear cells and decreased levels of IL- 8 in TBLF from premature neonates with respiratory distress. The anti-inflammatory effects of corticosteroids may be mediated through NF- $\kappa$ B. (Pediatr Res 59: 811-815, 2006)
\end{abstract}

$\mathrm{N}$ uclear Factor-kappaB $(\mathrm{NF}-\kappa \mathrm{B})$ is a family of DNAbinding proteins that are required for transcription of many pro-inflammatory mediators (1-4). In un-stimulated cells, NF- $\kappa \mathrm{B}$ is found in the cytoplasm as an inactive nonDNA-binding form, complexed with the inhibitor protein Inhibitory kappa B (I $\kappa$ B) (1-4). Binding of NF- $\kappa$ B with anchoring protein $\mathrm{I} \kappa \mathrm{B}$, prevents its translocation into the

Received September 14, 2005; accepted January 18, 2006.

Correspondence: Zubair Aghai, M.D., Cooper University Hospital-UMDNJ, 755 Dorrance Bldg., One Cooper Plaza, Camden, NJ 08103; e-mail: aghaizubair@ cooperhealth.edu

This work was supported in large part by the grant from Ronald McDonald House of Southern New Jersey. Reagents and instruments to measure cytokines were kindly provided by the DPC Inc., Los Angeles, CA.

This study was presented in part as a poster at the Annual Meeting of Society of Pediatric Research, San Francisco, CA, May, 2004.

DOI: 10.1203/01.pdr.0000219120.92049.b3 nucleus. Stimulation of the cells by cytokines IL- $1 \beta$ and tumor necrosis factor-alpha (TNF- $\alpha$ ) and Reactive Oxygen Species (ROS), leads to activation and translocation of NF- $\kappa$ B into the nucleus (1-4). Activated NF- $\kappa \mathrm{B}$, after its translocation into the nucleus, binds with promoter regions of target genes and increases transcription of inflammatory mediators. NF- $\kappa \mathrm{B}$ plays an important role in the pathogenesis of acute lung inflammation $(1,2)$. NF- $\kappa$ B regulates gene expression of proinflammatory cytokines, chemokines, and adhesion molecules (1). In adults with ARDS, there is enhanced activation of NF- $\kappa \mathrm{B}$ in alveolar macrophages recovered by bronchoalveolar lavage (5). NF- $\kappa \mathrm{B}$ activation is also increased in key locations in the airways of adult asthmatic patients (6). Cao et al. reported that NF- $\kappa \mathrm{B}$ is expressed in alveolar macrophages of mechanically ventilated pre-term neonates with respiratory distress syndrome (RDS) (7). More recently, Cheah et al. observed that activation of NF- $\kappa \mathrm{B}$ in pulmonary leukocytes from premature infants with RDS is associated with chorioamnionitis and ureaplasma urealyticum colonization (8). Increased expression of NF- $\kappa$ B by the cells of tracheobronchial lavage fluid (TBLF) in extremely low birth weight neonates is associated with increased mortality and increased severity of bronchopulmonary dysplasia (BPD) (9). Thus, it appears that activation of NF- $\kappa \mathrm{B}$ is central to the development of pulmonary inflammation and lung injury.

NF- $\kappa \mathrm{B}$ activation is a regulated process in the very early steps of lung inflammation. Activation of NF- $\kappa \mathrm{B}$ leads to coordinated expression of various mediators of inflammation and perpetuation of the inflammatory response $(1,2)$. Therefore, NF- $\kappa \mathrm{B}$ is an obvious target for anti-inflammatory treatment. Glucocorticoids inhibit the activation of NF- $\kappa \mathrm{B}$ in

Abbreviations: BPD, Bronchopulmonary Dysplasia; FiO2, Fractional Inspired Oxygen; IאB, Inhibitory Kappa B; MAP, Mean Airway Pressure; NF-кB, Nuclear Factor-kappaB; PMN, Polymorphonuclear; TBLF, Tracheobronchial Lavage Fluid 
various mammalian inflammatory and lung epithelial cells (10). Treatment of polymorphonuclear (PMN) leukocytes of the newborn with dexamethasone inhibits NF- $\kappa$ B activation (11). Glucocorticoid therapy in premature neonates with RDS decreases pro-inflammatory cytokines (12), however the molecular mechanism is not known. Suppression of proinflammatory cytokines by steroids may be mediated by inhibition of transcription factor NF- $\kappa \mathrm{B}$. However, to our knowledge, there is no data on the inhibition of NF- $\kappa$ B by steroids in premature neonates with respiratory distress.

The objective of this study was to evaluate the effect of dexamethasone therapy on the expression of NF- $\kappa \mathrm{B}$ by the cells in TBLF from premature neonates with respiratory distress. We hypothesized that dexamethasone therapy suppresses the activation of NF- $\kappa \mathrm{B}$ in the cells of TBLF from premature neonates with respiratory distress. We further hypothesized that decreased expression of NF- $\kappa \mathrm{B}$ after dexamethasone therapy is associated with decreased proinflammatory mediators in TBLF in premature neonates.

\section{DESIGN/METHODS}

Study population. The study was conducted in a 39-bed, level III Neonatal Intensive Care Unit (NICU) at Cooper University Hospital in Camden, New Jersey, between March, 2003 and October, 2004. The Institutional Review Committee approved this study and parents signed a written informed consent.

Infants born before $32 \mathrm{wk}$ gestation, requiring mechanical ventilatory support and receiving dexamethasone for severe lung disease were eligible for participation in the study. The decision to treat an infant with dexamethasone was made by an attending neonatologist taking care of the baby. Infants received a $9 \mathrm{~d}$ weaning course of dexamethasone $(0.3 \mathrm{mg} / \mathrm{kg}$ for $3 \mathrm{~d}, 0.2$ $\mathrm{mg} / \mathrm{kg}$ for $3 \mathrm{~d}$ and $0.1 \mathrm{mg} / \mathrm{kg}$ for $3 \mathrm{~d}$ ). Infants with active sepsis, congenital heart disease and/or any congenital anatomic abnormality of the lungs were excluded. Relevant clinical data were collected from the patient's chart.

Tracheobronchial lavage fluid. Tracheo-bronchial lavage fluid (TBLF) was collected before and $48-72 \mathrm{~h}$ after starting dexamethasone therapy. Tracheobronchial lavage fluid was obtained by instilling $0.5 \mathrm{~mL}$ of normal saline into the infant's endotracheal tube and suctioning the residue with $5 \mathrm{~F}$ suction catheter after two or three ventilator breaths. The suction catheter was passed to a standardized length of $0.5-1 \mathrm{~cm}$ beyond the tip of the endotracheal tube. This method of collection is widely used in neonates to collect TBLF $(2-5,12,13)$. The procedure was repeated $2-3$ times. The suction catheter was flushed with $0.5 \mathrm{~mL}$ of normal saline after each suctioning episode to collect the residual sample in the catheter. The samples were immediately transported to the laboratory on ice and processed within half an hour in the laboratory. Cells were counted using a hemocytometer. Viability test was performed on initial samples using trypan blue, $98-100 \%$ of cells were viable. The TBLF samples were centrifuged at $4^{\circ} \mathrm{C}$ for $10 \mathrm{~min}$ at $300 \mathrm{~g}$. The supernatant was collected, divided into aliquots and frozen at $-70^{\circ} \mathrm{C}$. The cell pellet from TBLF was used to make cytospin slides $\left(5 \times 10^{4}\right.$ cells/slide $)$ using a Cytospin ${ }^{\circledR}$ centrifuge (ThermoShandon). Slides were fixed in ice-cold acetone, wrapped in foil and stored at $-70^{\circ} \mathrm{C}$ for future use.

Papanicolaou stain. In order to obtain differential cell counts, the cytospin slides were stained using the Papanicolaou method.

Immunocytochemistry. Acetone-fixed cytospin slides were allowed to warm to room temperature and then submerged in tris-buffered saline with $0.05 \%$ Tween 20 for $15 \mathrm{~min}$. The slides were blocked before immunostaining with $3 \% \mathrm{H}_{2} \mathrm{O}_{2}$ (to inhibit endogenous peroxidase activity) and $10 \%$ goat serum to prevent nonspecific binding from the secondary link antibody.

Immunohistochemical staining for expression of p65 subunit of NF- $\kappa \mathrm{B}$ was performed using monoclonal mouse anti-human NF- $\kappa$ B antibodies (Santa Cruz Biotechnology, Inc., Santa Cruz, CA). Detection used a labeled streptavidin-biotin methodology using chemicals from Zymed Laboratories (San Francisco, CA), DAB chromogen from BioFx (Owings Mills, MD) and a Dako Autostainer (DakoCytomation, Carpinteria, CA). Activation of the p65 protein was detected as brown positively stained cells. Negative controls were performed using non-immunized mouse IgG1 in place of the NF- $\kappa \mathrm{B}$ antibody. The tissue from carcinoma of the breast was used for a positive control.
Data analysis. Localization of NF- $\kappa \mathrm{B}$ in TBLF cells was performed manually as well as by digital image analysis.

Manual count for localization of $\boldsymbol{N F}-\boldsymbol{\kappa} \boldsymbol{B}$. Two independent, blinded observers reviewed the slides. A total of four hundred cells in four different fields were counted. Depending on the intensity of staining, cells were scored as $0=$ no staining, $1=$ mild stain, $2=$ moderate stain and $3=$ severe staining. The percent and intensity of stained cells were calculated using the following formula:

Intensity of stained cells $=\{(1 \times$ number of cells with mild staining $)+$ $(2 \times$ number of cells with moderate staining $)+(3 \times$ number of cells with severe staining)\}/ Total number of cells.

Digital image analysis. Immunostained slides were analyzed via digital image analysis using ImagePro-Plus (Media Cybernetics, Silver Spring, MD). Images were captured through an Olympus $\mathrm{BH}-2$ microscope fitted with a Magnafire SP video camera (Olympus America, Melville, NY). Four different fields were captured from each slide. Immunohistochemical measurement parameters included total cellular area, total stained area, and integrated OD (IOD, a measure of total stained area and intensity of stain). NF- $\kappa \mathrm{B}$ expression is reported as an intensity stain index (ISI). The ISI is defined as IOD divided by total cellular area. Percent stained area defined as total stained area divided by total cellular area $\mathbf{x} 100$, was also calculated.

Localization of $N F-\kappa B$ in the cytoplasm and the nuclei. During analysis cells were classified as mononuclear (macrophage and lymphocyte) or PMN cells. The majority of the mononuclear cells with nuclear staining were macrophages with occasional nuclear staining in lymphocytes. However, it was not possible to differentiate between lymphocytes and macrophages if the cytoplasm was not stained with NF- $\kappa$ B. Epithelial cells were too few and were not included in analysis.

Three independent blinded observers carried scoring for nuclear localization. Observers chose their own area for cell counts. At least 200 cells were counted. Each cell was first classified as mononuclear or PMN, then the cell was further scored as no staining, cytoplasm only staining (nonactivated NF- $\kappa$ B) and nuclear \pm cytoplasm staining (activated NF- $\kappa$ B). Percentages of PMN's and mononuclear cells with stained cytoplasm and nuclei were calculated.

Cytokine assays. The concentrations of IL- $1 \beta$, IL-6, IL- 8 and TNF- $\alpha$ in TBLF were determined by a solid phase, two-site sequential chemiluminescent immunometric automated assay (Immulyte, DPC Inc., Los Angeles, CA). The control, intra-assay and inter-assay variability values were within $10 \%$. The upper detection limits for IL- $1 \beta$, IL- 6 and TNF- $\alpha$ were $1,000 \mathrm{pg} / \mathrm{mL}$ and $7,500 \mathrm{pg} / \mathrm{mL}$ for IL-8. Analytical sensitivity for IL-6, TNF- $\alpha$, IL-1 $\beta$ and IL-8 were $2,1.7,1.5$ and $2 \mathrm{pg} / \mathrm{mL}$, respectively.

Statistical analysis. Statistics were performed using Sigma Stat 3.1 for Windows statistical package (Systat Software, Inc., Point Richmond, CA). The manual count between observers was correlated using the Pearson correlation coefficient (r). Similarly the staining index calculated by manual count and digital image analysis was correlated using the Pearson correlation coefficient ( $\mathrm{r}$ ). Comparisons between groups were performed using Student $t$-test and Mann-Whitney $U$-test for continuous data and $\chi^{2}$ or Fisher's exact test for categorical data. The difference was considered significant for $p<$ 0.05 .

\section{RESULTS}

Nineteen premature neonates received 21 courses of steroids during the study period. Clinical characteristics of the study population are summarized in Table 1 . The mean age of starting steroid therapy was $33 \pm 15 \mathrm{~d}$.

Table 1. Clinical characteristics of the study population $(\mathrm{n}=19)$

$\begin{array}{lc}\text { Birth Weight (Grams) } & 714 \pm 105 \\ \text { Gestational Age (Weeks) } & 25.0 \pm 1.2 \\ \text { Sex (\% Male) } & 13(68) \\ \text { Race (\% Caucasian) } & 8(42) \\ \text { Prenatal steroids (\%) } & 16(84) \\ \text { Histological chorioamnionitis (\%) } & 9(47 \%) \\ \text { Days on ventilator } & 59 \pm 24 \\ \text { Mortality at 36 weeks PCA (\%) } & 3(16) \\ \text { Survival without BPD at 36 weeks PCA } & 0 \\ \text { Age of starting steroids (Days) } & 33 \pm 15\end{array}$

Values are expressed as mean $\pm \mathrm{SD}$. 
Fractional inspired oxygen (FiO2) and Mean Airway Pressure (MAP) (Mean $\pm \mathrm{SD}$ ) before starting dexamethasone were $0.64 \pm 0.27$ and $14.3 \pm 3.9$, respectively. Dexamethosone therapy significantly decreased the MAP $(11.6 \pm 3.7$, $p=0.001)$. There was also a trend toward lower FiO2 (0.49 $\pm 0.25, p=0.07)$ after steroid therapy.

Total cell count was lower $\left(70.3 \pm 73 \times 10^{4}\right)$ after starting dexamethasone compared with before dexamethasone treatment $\left(89.0 \pm 112.8 \times 10^{4}\right)$, however this difference was not statistically significant $(p=0.20)$. Papanicolaou stain was performed on slides from twelve infants to obtain differential cell counts. There was no significant difference in differential cell counts before and after dexamethasone therapy (Table 2). Polymorphonuclear cells were the predominant cells both before $(56.9 \pm 14.9 \%)$ as well as after $(58.6 \pm 9.8 \%)$ dexamethasone therapy.

In each TBLF sample, staining was observed in the cytoplasm and nuclei of the cells indicating localization of p65 sub-unit of NF- $\kappa$ B (Fig. 1 and 2). On manual count, the percent of the cells stained with $\mathrm{NF}-\kappa \mathrm{B}$ were significantly higher before starting dexamethasone $(63.3 \pm 23.4 \%)$ then after glucocorticoid therapy $(42.3 \pm 29.5 \%, p=0.017)$. Similarly the intensity index, indicating the severity of staining was significantly higher before starting dexamethasone $(130.37 \pm 70.4)$ compared with after steroid therapy $(74.3 \pm$ 62.8) $(p=0.01)$ (Fig. 2).

Immuno-stained slides were also analyzed using digital image analysis. Intensity staining index was significantly higher $(54.1 \pm 33.9)$ before starting dexamethasone when compared with during steroid therapy $(24.7 \pm 27.9)(p=$ $0.005)$. Similarly, the percent stained area was higher $(21.2 \pm$ $13.3 \%$ ) before starting dexamethasone when compared with during the therapy $(9.7 \pm 10.9 \%)(p=0.005)$. The ISI calculated by digital image analysis positively correlated with the staining index calculated by manual count $(\mathrm{r}=0.77, p<$ $0.001)$. The localization of NF- $\kappa \mathrm{B}$ was significantly decreased in the cytoplasm and the nuclei of mononuclear cells (alveolar macrophages) after dexamethasone therapy (Table 3). There was no significant difference in localization of NF- $\kappa \mathrm{B}$ in the cytoplasm and nuclei of PMN before and after dexamethasone therapy.

The levels of IL- $1 \beta$, IL- 6 , IL-8 and TNF- $\alpha$ were higher before starting dexamethasone compared with after steroid therapy (Fig. 3), however the level of significance was reached only for IL-8 $(p=0.014)$.

Table 2. Total $(\mathrm{n}=21)$ and differential $(\mathrm{n}=12)$ cell count before and after therapy with dexamethasone

\begin{tabular}{lccc}
\hline & $\begin{array}{c}\text { Before } \\
\text { dexamethasone }\end{array}$ & $\begin{array}{c}\text { After } \\
\text { dexamethasone }\end{array}$ & $p$-value \\
\hline Total cells (per mL) & $89.0 \pm 112.8 \times 10^{4}$ & $70.3 \pm 73 \times 10^{4}$ & 0.20 \\
Polymorphs (\%) & $56.9 \pm 14.9$ & $58.6 \pm 9.8$ & 0.57 \\
Macrophage (\%) & $31.3 \pm 15.0$ & $28.6 \pm 12.9$ & 0.41 \\
Lymphocytes (\%) & $8.6 \pm 3.3$ & $8.7 \pm 2.7$ & 0.94 \\
Epithelial cells (\%) & $3.3 \pm 1.4$ & $4.7 \pm 3.6$ & 0.18 \\
\hline
\end{tabular}

Values are expressed as mean $\pm \mathrm{SD}$.
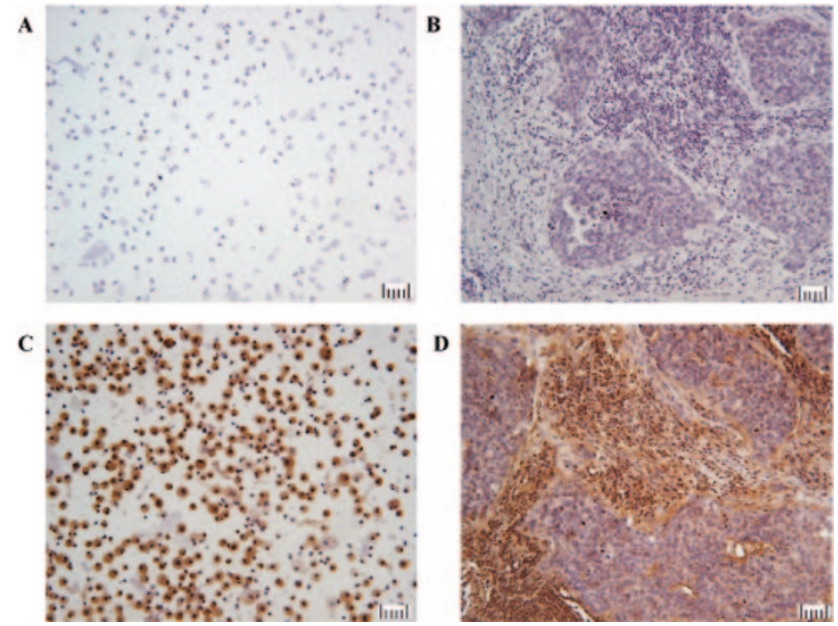

Figure 1. Localization of NF- $\kappa \mathrm{B}$ shown as brown staining on immunohistochemistry using mouse MAb directed against p65 subunit of NF- $\kappa \mathrm{B}$. A, C TBLF cells (A negative control without primary antibody), B, D tissue from carcinoma of breast (B, negative control; $\mathrm{D}$, positive control). NF- $\kappa \mathrm{B}$ is localized as a brown staining in the cytoplasm and the nuclei. (Space between two large bars $=50 \mu \mathrm{M}$ )

\section{DISCUSSION}

This study demonstrates that transcription factor NF- $\kappa$ B is expressed in the cellular component of TBLF from premature neonates with respiratory distress. NF- $\kappa \mathrm{B}$ is localized in the cytoplasm as well as the nuclei of PMN and mononuclear cells (alveolar macrophages). It is known that pro-inflammatory cytokines TNF- $\alpha$, IL-1 $\beta$, IL- 6 and IL- 8 are markedly elevated in TBLF from premature neonates with RDS who subsequently develop BPD (13-15). Activation of NF- $\kappa$ B by increasing transcription of pro-inflammatory mediators may have a central role in lung inflammation in premature neonates with respiratory distress. Recent reports from Cheah et al. and Bourbia et al. suggest the possible role of NF- $\kappa \mathrm{B}$ activation in neonatal lung injury and development of $\operatorname{BPD}(8,9)$. Our data

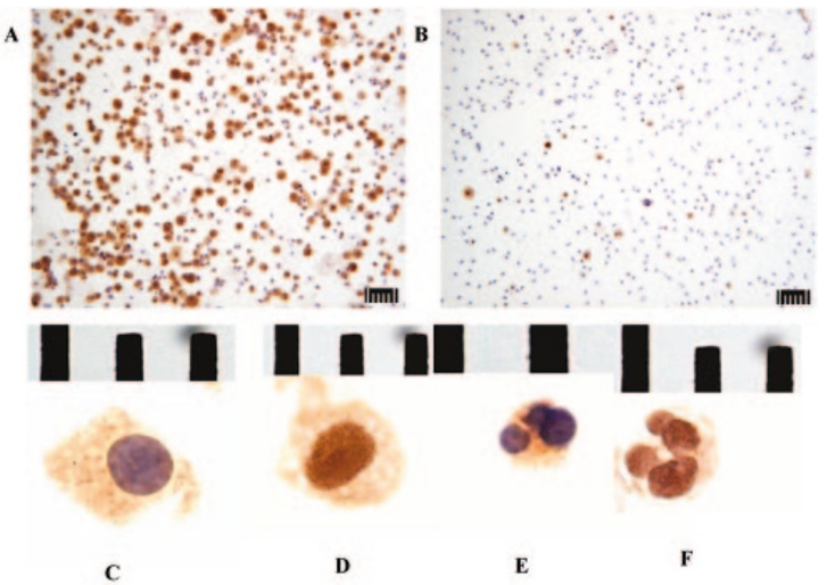

Figure 2. Localization of NF- $\kappa \mathrm{B}$ as a brown staining in TBLF cells before steroid therapy (A) and after dexamethasone (B). Staining for localization of $\mathrm{NF}-\kappa \mathrm{B}$ is significantly decreased after steroid therapy. Mononuclear cell and PMN with inactivated NF- $\kappa \mathrm{B}$ (brown staining in the cytoplasm but no staining in the nuclei) ( $\mathrm{C}$ and $\mathrm{E}$ ). Mononuclear cell and PMN with activated NF- $\kappa$ B (brown stained nuclei) (D and F) (Space between two bars $=10 \mu \mathrm{M}$ ) 
Table 3. Percent of the polymorphonuclear and monuclear cells with cytoplasm and nuclear staining before and after dexamethasone therapy (mean \pm standard deviation) $(\mathrm{n}=21)$

\begin{tabular}{|c|c|c|c|c|}
\hline & & Before dexamethasone & After dexamethasone & $p$-value \\
\hline \multirow[t]{3}{*}{ Polymorphonuclear cells } & Total stained cells $(\%)$ & $37.5 \pm 26.6$ & $32.7 \pm 16.4$ & 0.31 \\
\hline & Cells with cytoplasm stain (\%) & $36.1 \pm 24.6$ & $30.9 \pm 24.8$ & 0.21 \\
\hline & Cells with nuclear stain (\%) & $13.6 \pm 13.6$ & $13.5 \pm 14.0$ & 0.88 \\
\hline \multirow[t]{3}{*}{ Mononuclear cells } & Total stained cells $(\%)$ & $73.1 \pm 20.4$ & $64.1 \pm 27.6$ & 0.004 \\
\hline & Cells with cytoplasm stain (\%) & $66.8 \pm 19.1$ & $54.1 \pm 26.2$ & 0.004 \\
\hline & Cells with nuclear stain (\%) & $29.6 \pm 16.5$ & $18.1 \pm 13.9$ & 0.008 \\
\hline
\end{tabular}
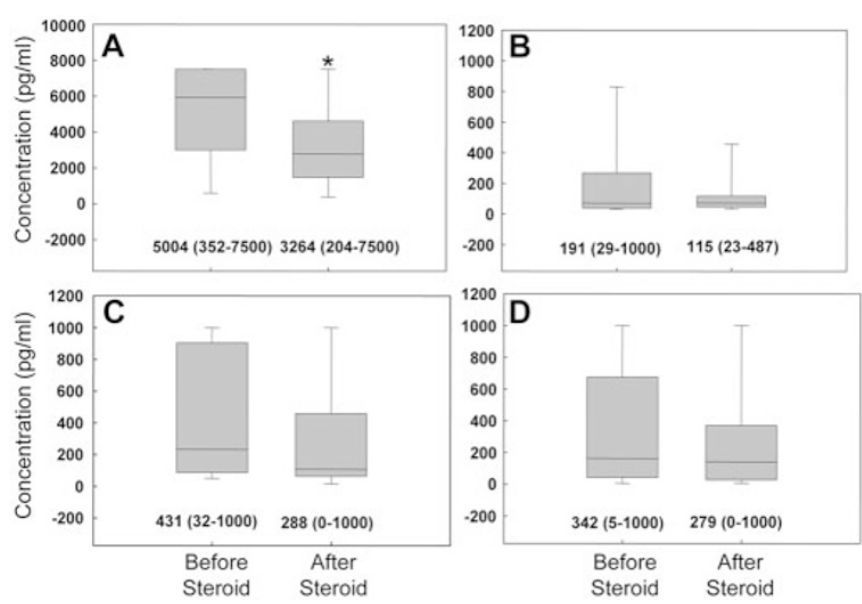

Figure 3. The levels of IL-8 (A), TNF- $\alpha(B)$, IL-6 (C), IL-1 $\beta(D)$ TBLF expressed in $\mathrm{pg} / \mathrm{mL}$ before and after dexamethasone therapy $(n=18)$. The median concentration of IL-8 was significantly lower after dexamethasone therapy. Box plot: the boundary of the box indicates the $25^{\text {th }}$ and $75^{\text {th }}$ percentiles, the line within the box marks the median value, and the error bars indicates the $5^{\text {th }}$ and $95^{\text {th }}$ percentile. The mean and range $(\mathrm{pg} / \mathrm{mL})$ are given below each box data. $* p=0.014$

indicates that therapy with dexamethasone suppressed the expression of NF- $\kappa \mathrm{B}$ in the cytoplasm and the nuclei of mononuclear cells from TBLF. The localization of NF- $\kappa$ B in the nuclei indicates its activation. Thus, our study suggests that steroid therapy inhibits activation of NF- $\kappa \mathrm{B}$ in the mononuclear cells from TBLF in premature neonates. We did not see significant suppression of NF- $\kappa \mathrm{B}$ expression in PMN. However, Vancurova et al. demonstrated inhibition of NF- $\kappa \mathrm{B}$ activation by dexamethasone in cord blood neutrophils (11).

The molecular mechanism of NF- $\kappa \mathrm{B}$ suppression by dexamethasone in our study population is unclear. Steroid inhibits $\mathrm{NF}-\kappa \mathrm{B}$ activation by either increasing cellular level of $\mathrm{I} \kappa \mathrm{B}-\alpha$ $(16-18)$ or by binding of NF- $\kappa \mathrm{B}$ with activated glucocorticoid receptor stoichoimetrically in the nuclei $(19,20)$. Increased $\mathrm{I} \kappa \mathrm{B}-\alpha$ activity will increase localization of NF- $\kappa \mathrm{B}$ in the cytoplasm. We did not see increased localization of NF- $\kappa$ B in the cytoplasm after dexamethasone therapy. In fact there was decreased localization of NF- $\kappa \mathrm{B}$ in the cytoplasm of mononuclear cells. The reason for this decreased localization of $\mathrm{NF}-\kappa \mathrm{B}$ is not clear, however, it may be pointed out here that $\mathrm{I} \kappa \mathrm{B}$ has putative NF- $\kappa \mathrm{B}$ site, and hence decreased NF- $\kappa \mathrm{B}$ in the nucleus may render I $\kappa \mathrm{B}$ less transcribed (less availability for glucocorticoids to induce NF- $\kappa \mathrm{B}$ ), and alter the dynamics of the p65 subunit of NF- $\kappa \mathrm{B} / \mathrm{I} \kappa \mathrm{B}$ ratio in the cytoplasm. This may account for less NF- $\kappa$ B in the cytoplasm as well as in the nucleus and steroid does not reverse this phenomenon.
Decreased expression of NF- $\kappa$ B in the mononuclear cells after dexamethasone therapy was also associated with decreased levels of pro-inflammatory cytokines in TBLF. Although concentrations of IL- $1 \beta$, IL- 6 and IL- 8 were lower after the steroid therapy, level of significance was reached only for IL-8. Further studies with a larger sample size may demonstrate significant change in other cytokines.

In this study, dexamethasone therapy not only suppressed the expression of NF- $\kappa \mathrm{B}$ but also decreased the concentrations of pro-inflammatory mediators. Decreased activation of NF- $\kappa \mathrm{B}$ was also associated with clinical improvement in neonates as reflected by lower ventilatory support (decreased $\mathrm{MAP}$ and FiO2). Thus, anti-inflammatory effects of steroids in preterm lungs may be mediated through NF- $\kappa \mathrm{B}$.

There was no significant difference in total and differential cell counts before and after steroid therapy in this study. Steroids are known to decrease lung inflammation by decreasing influx of inflammatory cells $(21,22)$. Possible explanations for no change in total and differential counts in this study are small sample size and early collection of samples (48-72 h) after starting dexamethasone. However, steroids is known to inhibit neutrophil apoptosis (23). Steroid therapy may decrease the influx of neutrophils in the lungs of premature infants but it also increases the survival of infiltrating cells by inhibiting apoptosis. We speculate that, this dual action of steroids on infiltrating cells can, in part, explain unchanged total and differential cell count in our study population. Furthermore, it is also likely that although dexamethasone is inhibiting inflammation, it was too early to detect any resolution of inflammatory cells at the time when the samples were taken.

We recognize some important limitations of this study:

1) NF- $\kappa \mathrm{B}$ was localized by immunohistochemistry in our study. Immunohistochemistry has its own limitation in quantification of NF- $\kappa \mathrm{B}$. Independent observers scored staining of NF- $\kappa \mathrm{B}$ as well as digital image analysis was used to quantify localization of NF- $\kappa$ B. Scores amongst observer as well as quantification with digital image analysis were strongly correlated.

2) Cytokines and NF- $\kappa$ B were measured in TBLF and potentially diluted. D'Angio et al. found a significant correlation in IL-8 and neutrophil counts between tracheal aspirate samples and broncheoalveolar lavage (BAL). They concluded that the tracheal aspirates might be a suitable substitute for BAL samples (24). It is controversial whether tracheal aspirate should be corrected for dilution in neonates (25). We followed the recommendation of European Respiratory Task Force on 
BAL in children and did not correct our result for dilution (25).

3) NF- $\kappa \mathrm{B}$ is a redox sensitive transcription factor. Neonates were on lower $\mathrm{FiO}_{2}$ (although not statistically significant) after dexamethasone therapy. The lower oxidant load with lower $\mathrm{FiO}_{2}$ may contribute to decreased NF- $\kappa \mathrm{B}$ activation. However, in our population, lower $\mathrm{FiO}_{2}$ was more likely the result than the cause of decreased NF- $\kappa \mathrm{B}$ activation.

In conclusion, this is the first study to demonstrate the suppression of NF- $\kappa \mathrm{B}$ by steroids in the cells of premature neonate with respiratory distress. This study also shows that the anti-inflammatory effect of dexamethasone in premature neonates may be mediated by NF- $\kappa \mathrm{B}$. Our ongoing research is to understand the mechanism of NF- $\kappa$ B inhibition by steroids in the lungs of premature neonates. This will help in the development of safer and more selective strategies to inhibit $\mathrm{NF}-\kappa \mathrm{B}$ activation in premature neonates with respiratory distress.

Acknowledgments. We thank Charlene Martin, R.N., Nancy Markiewicz, R.N., Valerie Gibson, R.N. and Maurine Remaly, R.N., B.S.N., for their help in screening babies for enrollment and collecting tracheal aspirates. We also thank Kee Pyon, Ph.D., for her help in analyzing data and reviewing the manuscript.

\section{REFERENCES}

1. Rahman I, MacNee W 1998 Role of transcription factors in inflammatory lung diseases. Thorax 53:601-612

2. Blackwell TS, Christman JW 1997 The role of nuclear factor-kappa B in cytokine gene regulation. Am J Respir Cell Mol Biol 17:3-9

3. Christman JW, Lancaster LH, Blackwell TS 1998 Nuclear factor kappa B: a pivotal role in the systemic inflammatory response syndrome and new target for therapy. Intensive Care Med 24:1131-1138

4. Christman JW, Sadikot RT, Blackwell TS 2000 The role of nuclear factor-kappa B in pulmonary diseases. Chest 117:1482-1487

5. Schwartz MD, Moore EE, Moore FA, Shenkar R, Moine P, Haenel JB, Abraham E 1996 Nuclear factor-kappa B is activated in alveolar macrophages from patients with acute respiratory distress syndrome. Crit Care Med 24:1285-1292

6. Barnes PJ, Adcock IM 1997 NF-kappa B: a pivotal role in asthma and a new target for therapy. Trends Pharmacol Sci 18:46-50

7. Cao L, Liu C, Cai B, Jia X, Kang L, Speer CP, Sun B 2004 Nuclear factor-kappa B expression in alveolar macrophages of mechanically ventilated neonates with respiratory distress syndrome. Biol Neonate 86:116-123
8. Cheah FC, Winterbourn CC, Darlow BA, Mocatta TJ, Vissers MC 2005 Nuclear factor kappaB activation in pulmonary leukocytes from infants with hyaline membrane disease: associations with chorioamnionitis and Ureaplasma urealyticum colonization. Pediatr Res 57:616-623

9. Bourbia A, Cruz MA, Rozycki HJ 2005 NF-kappaB in tracheal lavage fluid from intubated premature infants: association with inflammation, oxygen and outcome. Arch Dis Child Fetal Neonatal Ed 91:F36-F39

10. Barnes PJ, Adcock I 1993 Anti-inflammatory actions of steroids: molecular mechanisms. Trends Pharmacol Sci 14:436-441

11. Vancurova I, Bellani P, Davidson D 2001 Activation of nuclear factor-kappaB and its suppression by dexamethasone in polymorphonuclear leukocytes: newborn versus adult. Pediatr Res 49:257-262

12. Gupta GK, Cole CH, Abbasi S, Demissie S, Njinimbam C, Nielsen HC, Colton T, Frantz ID 3rd 2000 Effects of early inhaled beclomethasone therapy on tracheal aspirate inflammatory mediators IL- 8 and IL-1ra in ventilated preterm infants at risk for bronchopulmonary dysplasia. Pediatr Pulmonol 30:275-281.

13. Munshi UK, Niu JO, Siddiq MM, Parton LA 1997 Elevation of IL-8 and IL-6 precedes the influx of neutrophils in tracheal aspirates from preterm who develop bronchopulmonary dysplasia. Pediatr Pulmonol 5:331-336

14. Tullus K, Noack GW, Burman LG, Nilsson R, Wretlind B, Brauner A 1996 Elevated cytokines levels in tracheobronchial aspirate fluids from ventilator treated neonates with bronchopulmonary dysplasia. Eur J Pediatr 155:112-116

15. Jonsson B, Tullus K, Braunner A, Lu Y, Noack G 1997 Early increase of TNF alpha and IL-6 in tracheobronchial aspirate fluid indicator of subsequent chronic lung disease in preterm infants. Arch Dis Child Fetal Neonatal Ed 77:F198-F201

16. Cato AC, Wade E 1996 Molecular mechanisms of anti-inflammatory action of glucocorticoids. Bioessays 18:371-378

17. DiDonato JA, Saatcioglu F, Karin M 1996 Molecular mechanisms of immunosuppresssion and anti-inflammatory activities by glucocorticoids. Am J Respir Crit Care Med 154:S11-S15

18. Wissink S, van Heerde EC, vand der Burg B, van der Saag PT 1998 A dual mechanism mediates repression of NF-kappaB activity by glucocorticoids. Mol Endocrinol 12:355-363

19. Brostjan C, Anrather J, Csizmadia V, Stroka D, Soares M, Bach FH, Winkler H 1996 Glucocorticoid-mediated repression of NFkappaB activity in endothelial cells does not involve induction of IkappaBalpha synthesis. J Biol Chem 271:19612-19616

20. Heck S, Bender K, Kullmann M, Gottlicher M, Herrlich P, Cato AC 1997 IkappaB alpha-independent downregulation of NF-kappaB activity by glucocorticoid receptor. EMBO J 16:4698-4707

21. Groneck P, Reuss D, Gotze-Speer B, Speer CP 1993 Effects of dexamethasone on chemotactic activity and inflammatory mediators in tracheobronchial aspirates of preterm infants at risk for chronic lung disease. J Pediatr 122:938-944

22. Vento G, Matassa PG, Zecca E, Tortorolo L, Martelli M, De Carolis MP, Maggio L, Zini G, D'Onofrio G, Valentini S, Romagnoli C 2004 Effect of dexamethasone on tracheobronchial aspirate fluid cytology and pulmonary mechanics in preterm infants. Pharmacology 3:113-119

23. Meagher LC, Cousin JM, Seckl JR, Haslett C 1996 Opposing effects of glucocorticoids on the rate of apoptosis in neutrophilic and eosinophilic granulocytes. J. Immunol 156:4422-4428

24. D'Angio CT, Basavegowda K, Avissar NE, Finkelstein JN, Sinkin RA 2002 Comparison of tracheal aspirate and bronchoalveolar lavage specimens from premature infants. Biol Neonate 82:145-149

25. de Blic J, Midulla F, Barbato A, Clement A, Dab I, Eber E, Green C, Grigg J, Kotecha S, Kurland G, Pohunek P, Ratjen F, Rossi G 2000 Bronchoalveolar lavage in children. ERS Task Force on bronchoalveolar lavage in children. European Respiratory Society. Eur Respir J 15:217-231 